\title{
Rádio e convergência: uma abordagem pela economia política da comunicaçáa ${ }^{1}$
}

\begin{abstract}
RESUMO
O artigo traz questões relacionadas às novas lógicas de produção, distribuição e consumo de conteúdos radiofônicos em um ambiente de convergência midiática. A expansão do rádio rumo às plataformas digitais reconfigura as práticas comunicacionais, acelerando a concentração empresarial, mas também permitindo o surgimento de novos atores - notadamente, do setor de telecomunicações. Analisa-se, portanto, o novo lugar do rádio, indústria cultural que hesita entre as ondas eletromagnéticas e a multiplicidade de oferta de conteúdos e de canais de difusão do novo mundo digital. Estuda-se, aqui, o chamado rádio comercial, discutido em quatro âmbitos: 1) tecnológico; 2) empresarial; 3) profissional e 4) de conteúdos.
\end{abstract}

\section{PALAVRAS-CHAVE}

Rádio

Convergência

Economia Política da Comunicação

\begin{abstract}
This article brings questions about the new logics of production, distribution, and consumption of radio contents in a media convergence environment. Radio expansion towards digital platforms reconfigures communicational practices, accelerating capital concentration, but also creating opportunities for new actors -telecommunications companies, in particular. Furthermore, the new place of radio is analyzed, as a cultural industry that hesitates between old electromagnetic radiowaves broadcasting, and a new digital world of content offer multiplicity, and diffusion channels. The paper focuses on commercial radio, discussed in four dimensions: 1) technology; 2) business; 3) professional; and 4) contents.
\end{abstract}

\section{KEYWORDS}

Radio

Convergence

Political Economy of Communication

\section{Luiz Artur Ferraretto}

Professor do Centro de Ciências da Comunicação da UCS/RS/BR. luiz.ferraretto@uol.com.br

\section{Marcelo Kischinhevsky}

Professor da Faculdade de Comunicação Social da UER//RJ/BR. marcelokisch@gmail.com 
O que é rádio? A pergunta soou óbvia até o advento da internet. Há, é claro, outras tecnologias que integram o processo de convergência, mas a ascensão do computador como meio de acesso a conteúdos sonoros - informativos e/ou musicais tem peso relevante. Hoje, uma década e meia após a chamada world wide web ter adquirido feições comerciais e, cada vez mais, massivas, a questão reveste-se de importância tal que respondê-la aponta caminhos para a sobrevivência do meio e de sua utilização como negócio dentro da economia capitalista. De fato, há que associá-la não só à tecnologia, mas a um quadro mais amplo. $\mathrm{O}$ reposicionamento da radiodifusão sonora ocorre em um contexto no qual se faz necessário refletir sobre quatro âmbitos: 1) tecnológico, 2) empresarial, 3) profissional e 4) de conteúdo. Pretende-se, aqui, contribuir para a compreensão das novas lógicas de produção, comercialização, distribuição e consumo de conteúdos radiofônicos em tempos de convergência, em plena vigência do que Valério Cruz Brittos (1999) define como fase da multiplicidade da oferta.

No contexto da convergência assume-se - e, aqui, procura-se uma ampliação desta proposta uma pluralidade do rádio, como advoga Mariano Cebrián Herreros (2001, p. 47):

Escuta-se rádio em ondas médias, tropicais e curtas ou em frequência modulada, mas, desde a década passada, o veículo também se amalgama à TV por assinatura, seja por cabo ou DTH (direct to home); ao satélite, em uma modalidade paga exclusivamente dedicada ao áudio ou em outra, gratuita, pela captação, via antena parabólica, de sinais sem codificação de cadeias de emissoras em AM ou FM; e à internet, onde aparece com a rede mundial de computadores ora substituindo a função das antigas emissões em OC, ora oferecendo oportunidade para o surgimento das chamadas web radios ou, até mesmo, servindo de suporte a alternativas sonoras assincrônicas como o podcasting. Tal pluralidade pode ser estendida aos modos de processamento de sinais - analógico ou digital -, à definição legal da emissora - comercial, educativa ou comunitária -, ao conteúdo - jornalismo, popular, musical, cultural, religioso [...] (Ferraretto, 2007, f. 2-3).

É, tendo em mente esta realidade que se parte para estudar, portanto, o rádio no contexto da convergência midiática. $O$ presente artigo articula, ainda, reflexões desenvolvidas no Grupo de Pesquisa Rádio e Convergência, listado no CNPq e formado por pesquisadores dos estados de Minas Gerais, Rio Grande do Sul, Rio de Janeiro e São Paulo.

\section{Midiamorfose, acumulação flexível e cultura da convergência}

O multifacetado momento atual do rádio ganha maior compreensão se analisado a partir de algumas descrições da sociedade contemporânea elaboradas nas últimas décadas. Do ponto de vista empresarial, a acumulação flexível, descrita por David Harvey, auxilia no entendimento das transformações sofridas pelo mercado de radiodifusão sonora. A constatação de que emerge uma cultura da convergência, por Henry Jenkins, explica algumas mudanças de comportamento por parte do público. Já as teses envolvendo a chamada midiamorfose propaladas por Roger Fidler dão uma ideia mais precisa das alterações ocorridas no meio rádio sob a vigência da internet e de seus correlatos.

\section{0 multifacetado momento atual do rádio ganha maior compreensão se analisado a partir de algumas descrições da sociedade contemporânea elaboradas nas últimas décadas.}

Em The condition of postmodernity (1989), David Harvey descreve um novo regime de acumulação, com consequências políticas e sociais, que caracteriza o sistema capitalista após a crise do petróleo e seus reflexos na década de 1970.

A acumulação flexível [...] é marcada por um confronto direto com a rigidez do fordismo. Ela se apóia na flexibilidade dos processos de trabalho, dos mercados de trabalho, dos produtos e padrões de consumo. Caracteriza-se pelo surgimento de setores de produção inteiramente novos, novas maneiras de fornecimento de serviços financeiros, novos mercados e, sobretudo, taxas altamente intensificadas de inovação comercial, tecnológica e organizacional (Harvey, 1996, p. 140).

Nas indústrias culturais ligadas à radiodifusão sonora, a acumulação flexível caracteriza-se pelo aquecido mercado de arrendamento de radiofrequências, pela terceirização de espaços na programação, pelos frouxos mecanismos de gestão, pela precarização nas relações de trabalho 
e pelo acúmulo de funções imposto a radialistas e jornalistas. A desregulamentação não se resume às relações entre capital e trabalho ou à continuidade de práticas amparadas nos limbos legais gerados por imprecisões ou interpretações levianas do Código Brasileiro de Telecomunicações, de 1962, e de outros instrumentos legislativos correlatos e/ou posteriores². Há, após a privatização das companhias telefônicas, em 1998, a possibilidade de entrada, de forma mais intensa, desses grandes conglomerados no setor de radiodifusão, o que, de fato, já ocorre com a operadora Oi e sua rede de emissoras em FM.

Jenkins, em Convergence culture: where old and new media collide (2006), traz uma visão do processo de convergência centrada no comportamento do indivíduo como consumidor:

Em vez de falar sobre produtores e consumidores de mídia como ocupantes de papéis separados, podemos agora considerá-los como participantes interagindo de acordo com um novo conjunto de regras, que nenhum de nós entende por completo. [...] A convergência não ocorre por meio de aparelhos, por mais sofisticados que venham a ser. A convergência ocorre dentro dos cérebros de consumidores individuais e em suas interações sociais com outros (Jenkins, 2006, p. 28).

É necessária uma ponderação em relação ao que o autor chama, em dado momento, de cultura participativa e, em um contexto mais amplo, de convergente. Contrapõe-se, aqui, o argumento de que não apenas a habilidade franqueia maior ou menor acesso do cidadão a este novo mundo, mas são determinantes as suas condições socioeconômicas. No caso específico do rádio, constatam-se experiências da audiência na produção de conteúdos:

a) nas grandes cidades, ouvintes emulam serviços de reportagem ao se comunicarem com emissoras para informar, por exemplo, problemas de trânsito;

b) graças às tecnologias disponíveis, conteúdos sonoros são produzidos por amadores e distribuídos via podcasting;

c) retomando um associativismo comum nos primeiros momentos da radiodifusão, grupos de curiosos organizam-se repartindo custos e viabilizando, assim, web radios.

Fora isto, os dados existentes indicam um papel central destinado, no futuro do meio, ao telefone celular, cada vez menos aparelho móvel de telefonia, cada vez mais, como observa Jenkins (2006, p. 29), "o equivalente eletrônico do canivete suíço".

Sem a banda larga, a escuta de emissoras via internet não teria se desenvolvido. Aventa-se, ainda, a possibilidade, de um lado, de uma acelerada decadência das transmissões em amplitude modulada pela ausência deste tipo de recepção em celulares ou em MP3 payer

No que diz respeito à evolução do meio em si, é oportuno o trabalho de Roger Fidler (1997), Mediamorphosis, understanding new media. $\mathrm{O}$ autor utiliza o termo para descrever o processo de transformação dos meios no qual interagem necessidades percebidas, pressões políticas e concorrenciais, além de inovações sociais e tecnológicas.

Ao estudar o sistema de comunicação como um todo, veremos que os novos meios não surgem por geração espontânea, nem de modo independente. Aparecem gradualmente pela metamorfose dos meios antigos. E quando emergem novas formas de meios de comunicação, as antigas geralmente não deixam de existir, mas continuam evoluindo e se adaptando (Fidler, 1998, p. 57).

Com base no que Fidler (1998, p. 66) chama de princípios da midiamorfose, pode-se analisar o que ocorreu com o meio rádio em dois momentos:

a) o da introdução da TV no ambiente comunicacional;

b) o da vigência da internet.

Em ambas, aparecem os princípios (1) de coevolução e coexistência com o novo e (2) de metamorfose. A TV surge do acréscimo proporcionado pela imagem aos conteúdos radiofônicos. A internet incorpora tudo de todos os meios anteriores. O rádio, no passado, adapta-se à televisão, fugindo da concorrência pela segmentação do conteúdo e pela alteração do seu prime time, que passa da noite para a manhã, e, graças à transistorização, pela mobilidade do receptor. E, na contemporaneidade, usa a web como fonte de conteúdo e suporte de transmissão. Caracterizado pela ideia de que as formas novas carregam os traços dominantes das que lhe são anteriores, o princípio (3) de propagação, configura-se na 
transposição de conteúdos para a TV e, no último decênio, na constante utilização do áudio na internet tanto em modalidades que o rádio, gradativamente, incorpora como suas - as emissoras exclusivas da web e os programas distribuídos por podcasting - quanto em outras - os canais de música em portais, por exemplo.

O princípio (4) de sobrevivência do meio é quase autoexplicativo. Os meios são compelidos à adaptação e à evolução. $\mathrm{O}$ rádio tem, assim, procurado se amalgamar à internet e ao celular, mesmo que emissoras mais tradicionais demonstrem dificuldade em reconhecer esta tendência. Isto vai também ao encontro do princípio (5) de oportunidade e necessidade. Sem a banda larga, a escuta de emissoras via internet não teria se desenvolvido. Aventa-se, ainda, a possibilidade, de um lado, de uma acelerada decadência das transmissões em amplitude modulada pela ausência deste tipo de recepção em celulares ou em MP3 players, e, em sentido contrário, da recuperação das estações AM pela veiculação via internet e recepção em telefones de terceira geração ou mesmo pela cessão de espaço na faixa FM, quando da migração do analógico para o digital. Em um ou em outro, pode-se fazer presente o princípio (6) de Fidler, o de adoção postergada, segundo o qual as novas tecnologias sempre tardam mais do que o esperado para se converterem em êxitos comerciais.

\section{Múltiplas dimensões da convergência}

Pesquisadores brasileiros têm se dedicado a delimitar o campo da convergência, estudando metodologias e modelos que possam dar-lhe conta. É o caso de Suzana Barbosa (2009), que exemplifica a necessidade de ir além do viés tecnológico-digital. Neste sentido, toma-se por base, a exemplo desta pesquisadora, o estudo desenvolvido por um grupo de 24 pesquisadores espanhóis dentro do projeto Convergencia Digital en los Medios de Comunicación en España (20062009), financiado pelo Ministério da Educação e Ciência daquele país. Nele, a convergência, no âmbito do jornalismo - e, defende-se aqui, a aplicação destas formulações no meio rádio como um todo -, é vista como:

Um processo multidimensional que, facilitado pela implantação generalizada das tecnologias digitais de telecomunicação, afeta, no âmbito tecnológico, empresarial, profissional e editorial, os meios de comunicação, propician- do uma integração de ferramentas, espaços, métodos de trabalho e linguagens anteriormente separados, de modo que os jornalistas elaboram conteúdos que se distribuem por múltiplas plataformas, mediante as linguagens próprias de cada uma delas (García Avilés et al, apud Salaverría, García Avilés, 2008, p. 35).

Parte-se, portanto, para a análise de âmbitos propostos para a convergência jornalística, aqui transpostos para o rádio:

a) Tecnológico - Engloba a infraestrutura de produção, distribuição e recepção de conteúdos em suportes digitais, tais como computadores, gravadores, softwares de edição e gestão de conteúdos, bases de dados, redes de fibra óptica etc.

b) Empresarial - Compreende a origem e a composição dos capitais que controlam os grupos de comunicação, suas alianças, fusões e aquisições, participações societárias cruzadas etc.

c) Profissional - A integração de estruturas para produção de conteúdos a serem distribuídos em múltiplos suportes, as mudanças nas rotinas e nas relações de trabalho e as questões relacionadas à formação e à qualificação de mão-de-obra em ambiente multimídia.

d)Dos conteúdos - A produção de conteúdos, com a exploração de novas linguagens e formatos possibilitados pela hibridização de formas simbólicas desenvolvidas para difusão em multiplataforma.

Toca-discos para os bolachõesde vinil, gravadores de rolo, cartuchos e cassetes de fita magnética deram lugar, sucessivamente, a aparelhos rodando Digita Audo Tapes(DATs), MriDiscs(MDs), Compact Diss(CDs) ou uma variedade de outros formatos com denominações comerciais concorrentes até que o armazenamento migrasse quase integralmente para os discos rígidos de computadores, tornando obsoletas mídias físicas.

No âmbito tecnológico, os modos de produção radiofônica foram redefinidos desde os anos 1980. Toca-discos para os bolachões de vinil, gravadores de rolo, cartuchos e cassetes de 
fita magnética deram lugar, sucessivamente, a aparelhos rodando Digital Audio Tapes (DATs), MiniDiscs (MDs), Compact Discs (CDs) ou uma variedade de outros formatos com denominações comerciais concorrentes até que o armazenamento migrasse quase integralmente para os discos rígidos de computadores, tornando obsoletas mídias físicas. A informatização agilizou o acesso a dados e a elaboração de conteúdos, acarretando, do ponto de vista empresarial, maior produtividade. A evolução das telecomunicações também foi decisiva na capacidade do rádio de realizar transmissões de eventos ao vivo, bem como na formação de redes de abrangência nacional.

No âmbito empresarial, desde os anos 1970, a indústria de radiodifusão sonora reformulou-se, vivenciando acelerado processo de concentração. Verificam-se articulações frequentes no campo da propriedade cruzada dos meios, visando controlar, simultaneamente, jornais, emissoras de rádio e/ou estações de TV. Já sob a vigência da internet, grandes grupos expandem sua esfera de influência e, por vezes, tentam parcerias com conglomerados internacionais nas áreas de TV por assinatura e telecomunicações. Em segmentos mais específicos, atuam algumas pequenas e médias empresas. O menor porte, contudo, não impede, em casos determinados, o sucesso de seus empreendimentos na área de radiodifusão sonora e garante a sobrevivência do meio, com forte característica local, no interior do país.

Verifica-se, ao se analisar o âmbito profissional, que radialistas e jornalistas têm sido submetidos, nas emissoras comerciais, a regimes abusivos de plantão, sem compensação em termos de folgas ou pagamento de horas extras, além de sofrerem com a baixa remuneração e com o acúmulo de funções. Trabalhadores de áreas técnicas, como edição e operação de mesa de som, perdem seus empregos, enquanto repórteres são obrigados a editar as próprias reportagens diretamente no computador e apresentadores passam a comandar, no estúdio ao vivo, a entrada de comerciais, vinhetas e reportagens pré-gravadas. Programadores musicais, por sua vez, são substituídos por softwares e, em alguns casos, assumem a responsabilidade pela elaboração de playlists para diversas emissoras simultaneamente. Locutores perdem postos de trabalho pela crescente automação, em especial nas estações de FM - em certas faixas de horário, diversas emissoras mantêm programação musical aleatória gerada a partir de computadores (Kischinhevsky, 2008).

A convergência, contudo, não se circunscreve às emissoras de rádio já estabelecidas. No âmbito dos conteúdos, o novo ambiente midiático, com a emergência das chamadas mídias sociais e a crescente indistinção entre os pólos da emissão e da recepção, põe em xeque a "zona de conforto do razoavelmente bem-sucedido modelo de negócios das mídias tradicionais" (Saad Corrêa; Lima, 2009, p. 24). A capacidade das empresas de comunicação de gerar lucros passa hoje, portanto, não apenas pelos milhares de ouvintes por minuto de uma emissora de rádio, mas também pela sua capacidade de geração de fluxos comunicacionais entre participantes de redes sociais. Esta reconfiguração se evidencia na esfera da indústria da radiodifusão com a emergência do podcasting, modalidade de rádio sob demanda, em que o internauta pode baixar os arquivos de áudio para seu computador e/ ou para seu tocador multimídia. Tal prática tem potencial para emancipar o ouvinte, que passa a ter a alternativa de programar a recepção de conteúdos radiofônicos, abrindo um espaço antes inexistente para o surgimento de uma geração de receptores-emissores (Cebrían Herreros, 2001; Primo, 2005; Herschmann, Kischinhevsky, 2008). Com o decrescente custo das ferramentas digitais de criação, edição e veiculação, estes podcasters podem vir a competir com grandes empresas pela atenção do público, oferecendo informação e entretenimento em estratégias inéditas de comunicação de nicho.

No âmbito dbsconteúdbs o novo ambiente midiático, com a emergência das chamadas mídias sociais e a crescente indistinção entre os pólos da emissão e da recepção

A utilização da internet, passada a fase inicial dominada pelos pequenos empreendedores, desperta a atenção de grandes grupos empresariais. Emissoras tradicionais buscam expandir seus serviços para a rede mundial de computadores e vêm colhendo resultados promissores. A CBN, com sede em São Paulo, que detém audiência média de 25 mil ouvintes por minuto, somadas suas frequências em AM e FM, já contabiliza mais de 70 mil assinantes de podcasts de seus principais comentaristas. Outro indício desta aproximação crescente pode ser verificado na WHTZ, emissora 
em FM de Nova Iorque que funciona com o nome fantasia Z100. Operando no formato Top 40 $(\mathrm{CHR})^{3}$, com 5 milhões de ouvintes e o site mais acessado entre as estações dos Estados Unidos, apresenta intervalos comerciais diferenciados para o público que acompanha as transmissões via computador: o áudio de alguns spots - em geral, de anunciantes com presença global, como cartões de crédito e indústrias automobilísticas faz referência a imagens e a textos de banners, um procurando interagir com o outro.

\section{Esta reconfiguração se evidencia na esfera da} indústria da radiodifusão com a emergência do pockasting modalidade de rádio sob demanda, em que o internauta pode baixar os arquivos de áudio para seu computador e/ou para seu tocador multimídia.

\section{Considerações finais}

As possibilidades de integração do rádio às novas plataformas digitais, em um cenário de crescente convergência, reconfiguram a lógica do meio e impõem desafios. Há uma mudança central em desenvolvimento. É, sobremaneira, de teor conceitual. Como observado em outras oportunidades, o meio apresenta-se em modalidades que conformam, para além do hertziano, um rádio sem onda (Kischinhevsky, 2007), um rádio que pesquisadores e empresários, por motivos diversos e mesmo com resistência de vários deles, tendem a ver como uma linguagem - o texto na forma da fala, associado à música, aos efeitos sonoros e ao silêncio - independente do suporte (Ferraretto, 2009).

As demais implicações precisam ser refletidas a partir disto. E, no campo da economia política da comunicação, representam a configuração de uma indústria cultural específica no contexto das alterações em curso no sistema capitalista sob a influência das novas tecnologias. A digitalização tem acarretado substanciais alterações nos modos de criação, produção/edição, distribuição e consumo de formas simbólicas. Como descrito, com base em outros estudos (Bustamante et al., 2003, pp. 333-335), implica crescente desintermediação e franqueia acesso ao mercado para novos intermediários. Ao fim da primeira década do século 21, vale destacar alguns aspectos da realidade vivenciada pela indústria de radiodifusão sonora: a) os processos de digitalização ocorrem de forma assimétrica, acirrando a concentração empresarial e a desigualdade no acesso do público aos frutos das novas tecnologias;

b) a distribuição de conteúdo radiofônico ganha, de modo crescente, poderosos canais, com a maior velocidade de tráfego de dados e voz via internet e a disseminação dos telefones celulares ${ }^{4}$;

c) a formação de redes para transmissão de sinais em ondas hertzianas evoluiu na esteira de investimentos de umas poucas empresas de radiodifusão, que emergem, agora, como os grandes players de um mercado antes extremamente pulverizado;

d)novas cadeias de valor na produção de bens simbólicos são formadas, reforçando a relevância de grandes grupos empresariais, com maior capacidade de investimento em tecnologia;

e) abrem-se oportunidades para fornecedores de serviços e soluções, como portais de voz para interação com ouvintes e aplicativos, para sintonia de emissoras via redes de telecomunicações, e também para estratégias de branded content - em vez de programas patrocinados por grandes marcas, estações rebatizadas inauguram a comunicação direta empresa-consumidor (Mitsubishi FM, Oi FM, Sulamérica FM);

f) em sentido diverso e paradoxalmente, com o aprofundamento da segmentação proporcionado pelas redes digitais, crescem também os nichos de mercado para empreendedores, como redes sociais de base radiofônica (Last.fm, Blip.fm, Radiotube), podcasters, diretórios e fornecedores de soluções para distribuição de podcasts e web radios;

g) novos modelos de negócios e formatos começam a ser desenvolvidos no exterior (Cebrián, 2007), embora seja cedo para afirmar que trarão inovações na interação com os ouvintes.

A convergência midiática parece estar absorvendo o rádio, com grandes grupos empresariais se apropriando dos novos canais de difusão de áudio em formato digital. Resta avaliar as possibilidades trazidas pela transformação das audiências e das formas de recepção de conteúdos radiofônicos, com o desenvolvimento de novas linguagens, e garantir efetivamente o uso social dos novos meios de comunicação, realizando de 
modo pleno suas promessas emancipatórias e recuperando seu caráter cultural e educacional, livre das imposições mercantilistas que dominaram os padrões AM e FM.

É possível detectar, contudo, mais continuidades do que rupturas no desenvolvimento do rádio ao longo das últimas três décadas. A linguagem consolidada na irradiação hertziana persiste mesmo nas novas plataformas digitais e raras são as experiências inovadoras em termos de formato e sonoridade. Tipos de programas consagrados (informativos, musicais, mesas-redondas etc.) permanecem dominando as grades das emissoras abertas. Mesmo as possibilidades técnicas de ampliação da participação dos ouvintes são escassamente exploradas pelos empresários que, em 2010, seguiam em compasso de espera diante da indefinição em torno do padrão digital a ser adotado pelo Brasil.

\section{A digitalização tem acarretado substanciais alterações nos modos de criação, produção/edição, distribuição e consumo de formas simbólicas.}

Há que se considerar, ainda, a necessidade de revisão dos parâmetros legais do setor. É preciso pensar em novos marcos regulatórios para responder a demandas antigas e recentes. No plano conceitual, a Constituição Federal de 1988 estabelece três sistemas para a radiodifusão - privado, estatal e público -, mas sem regulamentação até o momento. O que dizer, então, da internet, em que não há regime de outorga nem legislação a estabelecer limites mínimos de veiculação de conteúdo noticioso ou máximos de anúncios? Ao findar a primeira década do século 21 , a diversidade deste rádio plural a avançar do hertziano para outras formas de distribuição do conteúdo torna, cada vez mais, imperativa esta redefinição.

\section{REFERÊNCIAS}

AGÊNCIA NACIONAL DE TELECOMUNICAÇÕES. Dezembro registra o melhor crescimento do ano em acessos móveis. 19 jan. 2010. Disponível em: <http://www.anatel.gov.br/>. Acesso em: 27 jan. 2010.

BARBOSA, Suzana. Convergência jornalística em curso: as iniciativas para integração de redações no Brasil. In: RODRIGUES, Cátia. (org.). Jornalismo on-line: modos de fazer. Rio de Janeiro: Pontifícia Universidade Católica do Rio de Janeiro/ Sulina, 2009. p. 35-55.

BRITTOS, Valério. Cruz. A televisão no Brasil, hoje: a multiplicidade da oferta. Comunicação E Sociedade, São Bernardo do Campo: Universidade Metodista de São Paulo, ano 20, n. 31, p. 9-34, 1999.

O rádio brasileiro na fase da multiplicidade da oferta. Verso E Reverso. São Leopoldo: Universidade do Vale do Rio dos Sinos, ano 16, n. 35, p. 31-54, jul.-dez. 2002.

. (org.). Comunicação na fase da multiplicidade da oferta. Porto Alegre: Nova Prova, 2006.

BUSTAMANTE RAMÍREZ, Enrique. (coord.). Hacia un nuevo sistema mundial de comunicación: las industrias culturales en la era digital. Barcelona: Gedisa, 2003.

CEBRIÁN HERREROS, Mariano. La radio en la convergencia multimedia. Barcelona: Gedisa, 2001.

. Modelos de radio, desarollos e innovaciones: del diálogo y participación a la interactividad. Madri: Fragua, 2007.

FERRARETTO, Luiz Artur. Possibilidades de convergência tecnológica: pistas para a compreensão do rádio e das formas do seu uso no século 21. In: SOCIEDADE BRASILEIRA DE ESTUDOS INTERDISCIPLINARES DA COMUNICAÇÃO. $30^{\circ}$ Congresso Brasileiro de Comunicação. Santos, $1^{\circ}$ set. 2007. $15 \mathrm{f}$

Alterações no modelo comunicacional radiofônico: perspectivas de conteúdo em um cenário de convergência tecnológica e multiplicidade da oferta. In: SOCIEDADE BRASILEIRA DE ESTUDOS INTERDISCIPLINARES DA COMUNICAÇÃO. $32^{\circ}$ Congresso Brasileiro de Comunicação. Curitiba, 5 set. 2009. $15 \mathrm{f}$.

Rádio e capitalismo no Brasil: uma abordagem histórica. In: HAUSSEN, Dóris Fagundes; BRITTOS, Valério Cruz. (org.). Economia política, Comunicação e cultura: aportes teóricos e temas emergentes na agenda política brasileira. Porto Alegre: Editora da Pontifícia Universidade Católica do Rio Grande do Sul, 2009. p. 93-112.

FIDLER, Roger. Mediamorfosis: compreender los nuevos medios. Buenos Aires: Granica, 1998.

GARCÍA AVILÉS, José Alberto; CARVAJAL, Miguel. Integrated and cross-media newsroom convergence: Two models of multimedia news production - The cases of Novotécnica and La Verdad Multimedia in Spain. In.: Convergence: The International Journal of Research into New Media Technologies. Londres: Sage, v. 14, n. 2, p. 221-39, 2008.

HARVEY, David. Condição pós-moderna: uma pesquisa sobre as origens da mudança cultural. 6. ed. São Paulo: Loyola, 1996.

HERSCHMANN, Micael \& KISCHINHEVSKY, Marcelo. A geração podcasting e os novos usos do rádio na sociedade do espetáculo e do entretenimento. Revista Famecos, Porto Alegre: Pontifícia Universidade Católica do Rio Grande do Sul, n. 37, p. 101-6, dez. 2008.

JENKINS, Henry. Cultura da convergência. São Paulo: Aleph, 2008.

KISCHINHEVSKY, Marcelo. O rádio sem onda - Convergência digital e novos desafios na radiodifusão. Rio de Janeiro: E-Papers, 2007.

Amigo ouvinte, o locutor perdeu o emprego: considerações sobre o processo de automação nas rádios FM do Rio de Janeiro. EPTIC On-line - Revista de Economía Política de las Tecnologías de la Información y Comunicación. Aracaju: Observatório de Economia e Comunicação da Universidade Federal de Sergipe, ano 9, v. 10, n. 3, set./dez. 
2008. Disponível em: <http://www2.eptic.com.br/arquivos/ Revistas/v.X,n.3,2008/13-MarceloKischinhevsky.pdf>. Acesso em: 23 nov. 2009.

MORAND, Carolina, gerente de Jornalismo da CBN no Rio de Janeiro. Entrevista pessoal em 22 de outubro de 2009.

PRIMO, Alex. Para além da emissão sonora: as interações no podcasting. Intexto, Porto Alegre: Universidade Federal do Rio Grande do Sul, v. 2, n. 13, 2005. Disponível em: <http://www.seer.ufrgs.br/index.php/intexto/ article/ view/4210/4466>. Acesso em: 23 nov. 2009.

SAAD CORRÊA, Elizabeth, CORRÊA, Hamilton. Convergência de mídias: primeiras contribuições para um modelo epistemológico e definição de metodologias de pesquisa. Verso $\mathcal{E}$ Reverso, São Leopoldo: Editora da Universidade do Vale do Rio dos Sinos, n. 50, 2008. Disponível em: $<$ http://www.versoereverso.unisinos.br/in-dex. php? $=14 \& s=9 \& a=115>$. Acesso em: 23 nov. 2009.

SAAD CORRÊA, Elizabeth; LIMA, Marcelo Coutinho. O impacto das mídias sociais nas empresas informativas, transformações no processo produtivo. In: BRITTOS, Valério. Cruz. (org.). Digitalização e práticas sociais: modulações e alternativas do audiovisual. São Leopoldo: Editora da Universidade do Vale do Rio dos Sinos, 2009. p. 23-41.

SALAVERRÍA, Ramón; GARCÍA AVILÉS, José Alberto. La convergencia tecnológica en los medios de comunicación: retos para el periodismo. Trípodos, Barcelona: Universitat Ramon Llull, n. 23, p. 31-47, 2008.

\section{NOTAS}

1 Versão de artigo apresentado no Grupo de Trabalho Economia Política e Políticas de Comunicação, no XIX Encontro Anual da Compós, realizado na Pontifícia Universidade Católica do Rio de Janeiro (PUC-Rio), em junho de 2010.

2 O estabelecimento, pelo código de 1962, de um mínimo de $5 \%$ de conteúdo informativo na programação das emissoras, por exemplo, é frequentemente desrespeitado. Na prática, funciona como um teto oficioso aos investimentos em radiojornalismo.

3 A sigla CHR - contemporary hit radio - associada ao Top 40 indica que a emissora dedica-se, basicamente, a rodar as 40 músicas de maior sucesso no momento.

4 Conforme estimativa da União Internacional de Telecomunicações (UIT), 2009 chegou ao fim com 4,6 bilhões de conexões telefônicas por celular e 600 milhões de usuários de banda larga móvel no mundo. No Brasil, em dezembro de 2009, existiam, segundo a Agência Nacional de Telecomunicações, 173,9 milhões de acessos habilitados no Serviço Móvel Pessoal (SMP), representando teledensidade de 90,55 para cada 100 habitantes. 